\section{A Secondary Alcohol Oxidase: a Component of a Polyvinyl Alcohol Degrading Enzyme Preparation}

\section{Makoto Morita and Yasuto Watanabe}

The Osaka Municipal Technical Research Institute, Kitaogimachi, Kitaku, Osaka

Received February 14, 1977

An enzymatic activity of degrading PVA* was found in a culture broth of an unidentified strain of Pseudomonas and the enzyme was purified to an apparently homogenous state judged from criteria of sedimentation and electrophoresis analyses. ${ }^{1,2)}$ Activity of this enzyme preparation on PVA could be followed

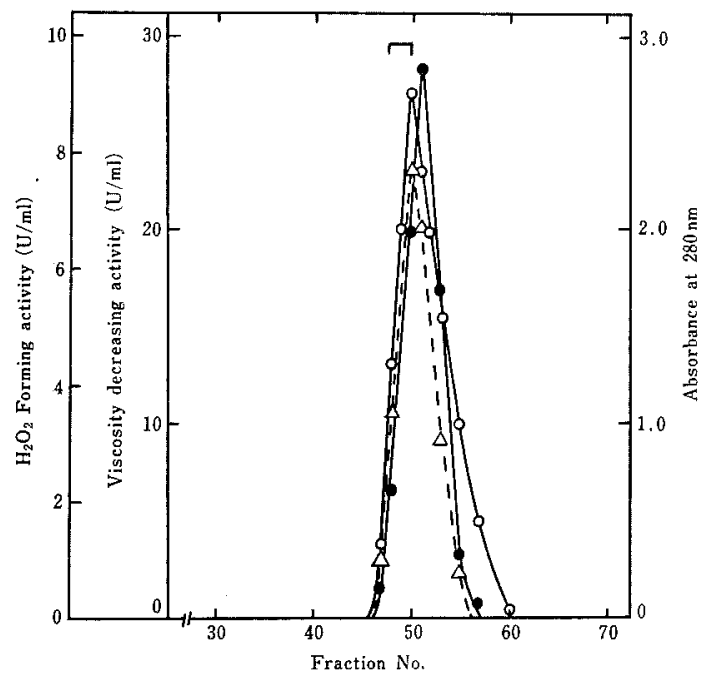

Frg. 1. Gel Filtration of a PVA Degrading Enzyme Preparation.

An enzyme preparation (total $\mathrm{OD}_{280}=70$ ) in $0.01 \mathrm{M}$ phosphate buffer ( $\mathrm{pH} 7.0$ ), which had been prepared from a culture broth by ammonium sulfate fractionation and SP-Sephadex chromatography, was applied to a column of Sephadex G-75 $(1.7 \times 140 \mathrm{~cm})$ and eluted with the buffer at a flow rate of $9.0 \mathrm{ml} / \mathrm{hr}$. Eluted solution was collected in fractions of 3.5 $\mathrm{ml} /$ tube. Fractions indicated by $\square$ were collected for further purification. $\triangle--\Delta, \mathrm{H}_{2} \mathrm{O}_{2}$ forming activity; - viscosity decreasing activity; $\mathrm{O}-\mathrm{O}$, $\mathrm{OD}_{280}$.

\footnotetext{
* Abbreviation used: PVA, polyvinyl alcohol.
}

by both formation of $\mathrm{H}_{2} \mathrm{O}_{2}$ and decrease in viscosity. However, detailed examinations of time courses of these activities revealed a slight lag of the decrease in viscosity at the beginning of reaction, and of elution profiles of these activities of the gel filtration revealed a slight discrepancy in the positions of their peaks (Fig. 1). These observations were reproducible and suggested the existence of another enzyme which might catalize the decrease in viscosity in an amount undetectable by means of disc electrophoresis.

In order to confirm that this is the case, an attempt was made to obtain a preparation which brought about $\mathrm{H}_{2} \mathrm{O}_{2}$ formation but not viscosity decrease by repeated gel filtrations on Sephadex G-75. Cultivation of the organism and purification of the enzyme up to the step of gel filtration were the same as described in the previous paper. ${ }^{2}$ The enzyme activity was assayed as described previously ${ }^{2}$ and a unit of the enzyme was defined as the amount which brought about a relative decrease in viscosity of $10 \%$ per hr or which produced $1 \mu \mathrm{mol}$ of $\mathrm{H}_{3} \mathrm{O}_{2}$ per min under the assay conditions.

A typical elution profile of the first gel filtration was shown in Fig. 1. Fractions collected from several runs were served as an original preparation for purification, which was then concentrated in a collodion bag and subjected to the second gel filtration. Fractions which had a high activity of $\mathrm{H}_{2} \mathrm{O}_{2}$ formation but an activity of viscosity decrease as low as possible were collected from several similar runs, concentrated and subjected to the third gel filtration. As seen from Fig. 2, fractions which showed the activity of $\mathrm{H}_{2} \mathrm{O}_{2}$ formation were essentially free from that of decreasing viscosity, although a complete removal was not possible. The fractions were combined and were served as a purified enzyme. The yield of activity was about $25 \%$ of the original preparation and there was almost no increase in the specific activity based on $\mathrm{H}_{2} \mathrm{O}_{2}$ formation. The purified enzyme was pink-colored as the original preparation. ${ }^{2)}$ The activity was highest in the range of $\mathrm{pH} 6.5 \sim 7.5$ and at $45^{\circ} \mathrm{C}$. 


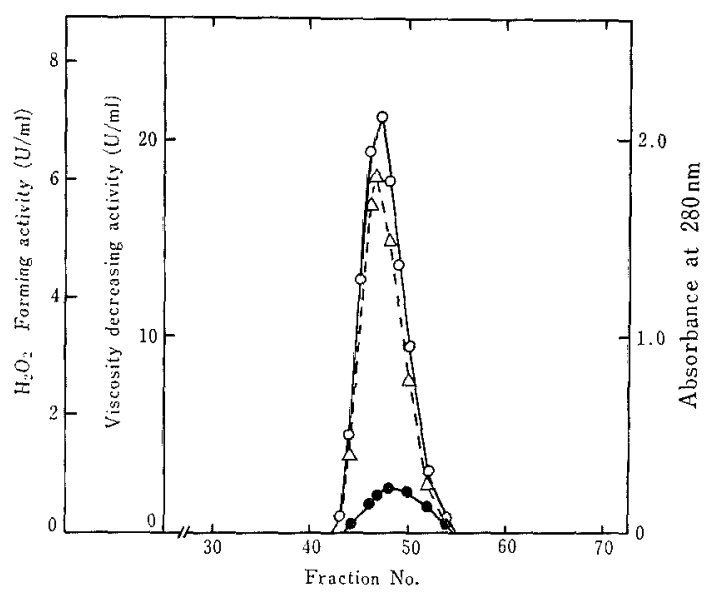

FIG. 2. Gel Filtration of a PVA Oxidizing Enzyme Preparation.

An enzyme preparation (total $\mathrm{OD}_{250}=45$ ) in $0.01 \mathrm{M}$ phosphate buffer ( $\mathrm{pH} 7.0$ ), which had been prepared from a culture broth by ammonium sulfate fractionation, SP-Sephadex chromatography and Sephadex G-75 gel filtration (twice), was applied to a column of Sephadex G-75 $(1.7 \times 140 \mathrm{~cm})$ and eluted with the buffer at a flow rate of $9.6 \mathrm{ml} / \mathrm{hr}$. Eluted solution was collected in fractions of $3.7 \mathrm{ml} /$ tube. $\triangle \cdots \triangle \mathrm{H}_{2} \mathrm{O}_{2}$ forming activity; - viscosity decreasing activity; $\mathrm{O}-\mathrm{O}, \mathrm{OD}_{\mathrm{280}}$.

An enzymatically oxidized PVA was prepared by incubating $20 \mathrm{ml}$ of $1 \%$ PVA in $0.05 \mathrm{M}$ phosphate buffer ( $\mathrm{pH} \mathrm{7.0)}$ ) with 0.5 units of the purified enzyme at $30^{\circ} \mathrm{C}$ for $1 \mathrm{hr}$ with shaking and used as substrate for detecting viscosity decreasing activity in the eluate of the first gel filtration. The activity was found to spread to the last half of the protein peak, which corresponds to fractions No. 55 60 in Fig. 1, where no decrease in viscosity was detected if untreated PVA was used as substrate. If the eluate was heated at $100^{\circ} \mathrm{C}$ for $10 \mathrm{~min}$, the decrease in viscosity did not occur.

Activities of the purified enzyme were examined on a variety of hydroxyl compounds and the results are shown in Table $I$. The enzyme seemed to act exclusively on compounds which have secondary hydroxyl group(s), except for some primary diols which have relatively longer carbon chains as far as examined. A certain length of carbon chain appeared to be required around the hydroxyl
Table I. Activity of the Purified Enzyme on VARIOUS HYDROXYL COMPOUNDS

Reactions were carried out in $2.0 \mathrm{mI}$ of $0.05 \mathrm{M}$ phosphate buffer ( $\mathrm{pH} \mathrm{7.0)}$ containing $5.0 \%$ of a hydroxyl compound listed in the table or $1.0 \%$ PVA and enzyme (0.08 units against PVA) at $30^{\circ} \mathrm{C}$ with shaking for $16 \mathrm{hr}$ for primary alcohols or for $6 \mathrm{hr}$ for secondary alcohols.

\begin{tabular}{lclr}
$\begin{array}{c}\text { Substrate } \\
\text { (Primary } \\
\text { alcohols) }\end{array}$ & $\begin{array}{c}\mathrm{H}_{2} \mathrm{O}_{2} \\
\text { nmoles/ } \\
\mathrm{ml} / \mathrm{hr}\end{array}$ & $\begin{array}{c}\text { Substrate } \\
\text { (Secondary } \\
\text { alcohols) }\end{array}$ & $\begin{array}{c}\mathrm{H}_{2} \mathrm{O}_{2} \\
\mathrm{nmoles} / \\
\mathrm{ml} / \mathrm{hr}\end{array}$ \\
\hline Methanol & 0 & 2-Propanol & 193 \\
Ethanol & 0 & 2-Butanol & 329 \\
1-Propanol & 6 & 2-Pentanol & 993 \\
1-Butanol & 3 & 3-Pentanol & 471 \\
1-Pentanol & 6 & 2-Hexanol & 786 \\
1-Hexanol & 6 & 3-Hexanol & 1040 \\
1-Heptanol & 5 & 2-Heptanol & 776 \\
1-Octanol & 6 & 3-Heptanol & 642 \\
1-Decanol & 4 & 4-Heptanol & 1370 \\
1,2-Ethanediol & 0 & 2-Octanol & 223 \\
1,3-Propanediol & 0 & 3-Octanol & 783 \\
1,4-Butanediol & 0 & 4-Octanol & 538 \\
1,5-Pentanediol & 5 & 2-Nonanol & 71 \\
1,6-Hexanediol & 21 & 3-Nonanol & 227 \\
1,8-Octanediol & 71 & 4-Nonanol & 370 \\
1,10-Decanediol & 20 & 5-Nonanol & 169 \\
& & 2-Decanol & 49 \\
PVA & 1040 & 4-Decanol & 122 \\
& & 5-Decanol & 100 \\
\hline & & &
\end{tabular}

group for the activity. 4-Heptanol was the best substrate so far examined and 4-heptanone was detected as a reaction product by means of gas-liquid chromatography of the reaction mixture under the following conditions: column, 5\% PEG-4000 on silanized celite 545 ( $80 \sim 100$ mesh, $0.3 \times 200 \mathrm{~cm}$ ); oven temp., $70^{\circ} \mathrm{C}(2 \mathrm{~min})$ and $70 \sim 100^{\circ} \mathrm{C}\left(5^{\circ} \mathrm{C}\right.$ per min); carrier gas, $\mathrm{N}_{2}$ (30 ml per min); instrument, Shimadzu Gas Chromatograph GC-4BM. Retention times of 4-heptanone and 4-heptanol were 3.8 and $7.1 \mathrm{~min}$, respectively. The enzyme may, therefore, be regarded as a secondary alcohol oxidase.

From these results, it may be considered that two enzymes, an oxidase and a hydrolase, exist in the culture broth which shows a PVA degrading activity and that the cleavage of carbon chain of PVA proceeds as the following successive reactions (1) and (2) catalyzed by the oxidase and the hydrolase, respectively. 


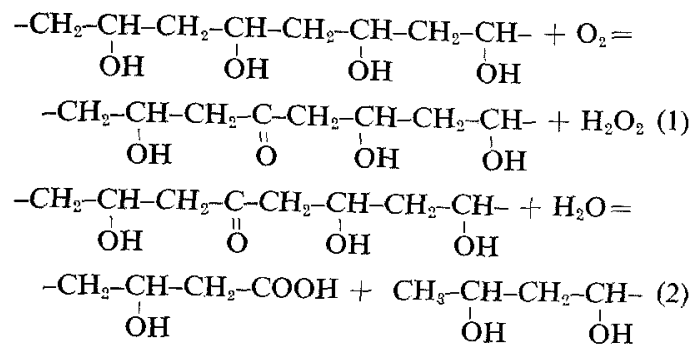

Suzuki has also reported recently a purified PVA-degrading enzyme from a strain of Pseudomonas, ${ }^{3)}$ which also exhibited a pale pink color and required oxygen for the reaction.
Acknowledgement. The authors wish to thank Dr. Y. Tsujisaka and Dr. N. Hamada for their valuable discussions.

\section{REFERENCES}

1) Y. Watanabe, M. Morita, N. Hamada and Y. Tsujisaka, Agric. Biol. Chem., 39, 2447 (1975).

2) Y. Watanabe, N. Hamada, M. Morita and $Y$. Tsujisaka, Arch. Biochem. Biophys., 174, 575 (1976).

3) T. Suzuki, Agric. Biol. Chem., 40, 497 (1976). 